\title{
Ischemic Compression After Trigger Point Injection Affect the Treatment of Myofascial Trigger Points
}

\author{
Soo A Kim, MD, Ki Young Oh, MD, Won Hyuck Choi, MD, In Kyum Kim, MD
}

\begin{abstract}
Department of Physical Medicine and Rehabilitation, Soonchunhyang University Cheonan Hospital,
\end{abstract} Soonchunhyang University College of Medicine, Cheonan, Korea

Objective To investigate the effects of trigger point injection with or without ischemic compression in treatment of myofascial trigger points in the upper trapezius muscle.

Methods Sixty patients with active myofascial trigger points in upper trapezius muscle were randomly divided into three groups: group $1(n=20)$ received only trigger point injections, group $2(n=20)$ received trigger point injections with 30 seconds of ischemic compression, and group $3(n=20)$ received trigger point injections with 60 seconds of ischemic compression. The visual analogue scale, pressure pain threshold, and range of motion of the neck were assessed before treatment, immediately after treatment, and 1 week after treatment. Korean Neck Disability Indexes were assessed before treatment and 1 week after treatment.

Results We found a significant improvement in all assessment parameters $(\mathrm{p}<0.05)$ in all groups. But, receiving trigger point injections with ischemic compression group showed significant improvement as compared with the receiving only trigger point injections group. And no significant differences between receiving 30 seconds of ischemic compression group and 60 seconds of ischemic compression group.

Conclusion This study demonstrated the effectiveness of ischemic compression for myofascial trigger point. Trigger point injections combined with ischemic compression shows better effects on treatment of myofascial trigger points in the upper trapezius muscle than the only trigger point injections therapy. But the duration of ischemic compression did not affect treatment of myofascial trigger point.

Keywords Myofascial pain syndromes, Ischemic compression, Trigger point injection

Received September 4, 2012; Accepted January 11, 2013

Corresponding author: In Kyum Kim

Department of Physical Medicine and Rehabilitation, Soonchunhyang University Cheonan Hospital, Soonchunhyang University College of Medicine, 31 Suncheonhyang 6-gil, Dongnam-gu, Cheonan 330-930, Korea

Tel: +82-41-570-2220, Fax: +82-41-576-3464, E-mail: c99849@schmc. ac.kr

(c) This is an open-access article distributed under the terms of the Creative Commons Attribution Non-Commercial License (http://creativecommons. org/licenses/by-nc/3.0) which permits unrestricted noncommercial use, distribution, and reproduction in any medium, provided the original work is properly cited.

Copyright $\odot 2013$ by Korean Academy of Rehabilitation Medicine

\section{INTRODUCTION}

Myofascial pain syndrome (MPS) is one of the most common musculoskeletal pain diseases and is characterized by myofascial trigger points, taut bands, and local twitch responses [1]. The myofascial trigger points arise from overuse, overload, emotional stress or severe traumas [2,3]. Although pathophysiology of MPS has not been completely understood, recent studies suggest that 
injured muscle fibers caused by overuse provide less oxygen and nutrition, and these deficiencies cause involuntary contractions [4].

There are various treatments for myofascial trigger points such as dry needling, local injection, ischemic compression, stretching, massage, and others [5-7]. Of these methods, dry needling or local injection which physically stimulates trigger points is efficient for MPS by reducing muscles shortening and increasing blood flows $[8,9]$. Hong [9] compared the efficacy of dry needling and lidocaine injection for myofascial trigger points and reported that those treatments are efficient only when induced with local twitch, regardless of drugs injected. Ischemic compression helps tissue recovery by reperfusion after transient blood flow occlusion [10].

Each of the trigger point injection therapy and ischemic compression was proved to be effective for trigger point treatments, but there has been no study which evaluated the efficacy of trigger point injections immediately followed by ischemic compression. Hence, in this study we evaluated the efficacy of combination of trigger point injections and ischemic compressions for patients with MPS of upper trapezius muscle.

\section{MATERIALS AND METHODS}

\section{Subjects}

Subjects were 60 outpatients from a rehabilitation medicine department who suffered from pains in upper trapezius muscles for more than 2 weeks and were diagnosed to have MPS, but did not undergo trigger point injections therapy before. Patients were prospectively assigned in order of visit to three different groups: trigger point injection only group (group 1), trigger point injection followed by 30 seconds of ischemic compression group (group 2), and trigger point injection followed by 60 seconds of ischemic compression group (group 3). Alcoholics, those who had contraindications of injections therapy such as infective diseases, antithrombotic agents and trauma, who had cognitive disorders or communication disorders, and who had cervical neuropathies, adhesive capsulitis of shoulder, fibromyalgia syndromes, and history of cervical or shoulder surgery were excluded.

\section{Methods}

Myofascial trigger point was diagnosed according to
Simon's criteria which include trigger points in one or more taut bands, referred pains of typical pattern, palpable or visible local twitch responses (LTR) induced by touching the most sensitive portion of taut bands, and restrictions of lateral bending of neck [11].

Trigger point injection therapy was performed by injecting $1 \%$ lidocaine into myofascial trigger points of upper trapezius muscle with a 25 -gauge needle and a $5-\mathrm{mL}$ syringe. Needle was advanced into the muscle till LTR was elicited and then $0.1 \mathrm{~mL}$ of lidocaine solution was injected. Thus, the needle was retracted and advanced again; the same procedure was repeated until no further LTR was elicited.

Ischemic compression was performed by compressing trigger points with tolerable intensity (visual analogue scale [VAS], 7-8) using pressure algometer, and when the degree of pain began to decrease, the intensity of compression increased. This procedure was performed for 30 seconds in group 2, and for 60 seconds in group 3.

Goniometric measurement of active lateral bending of the neck, VAS and pressure pain threshold (PPT) was measured before the treatment, immediately after the treatment, and 1 week after treatment. Efficacy of the treatment was evaluated by using the Korean version of Neck Disability Index (NDI) before treatment and 1 week after treatment [12]. All the measurements were performed by one examiner.

PPT is the degree of compression intensity at which the patients feels discomfort or pain instead of pressure sense. International Association of the Study of Pain defines PPT as the stimulation of the weakest intensity which a subject feels as pain [13]. PPT value of this definition have been proved to be reliable, reproducible and valid [14-16]. Before trigger point injection and ischemic compression, the examiner used Wagner FPX pressure algometer (Wagner Instruments, Greenwich, CT, USA) to measure PPT of the subjects and recorded the intensity of compression with which the subjects felt discomfort or pain instead of pressure sense.

Subjects involved in this study did not undergo physiotherapy and medication such as hot pack or ultrasonic therapy which may affect the results of the pain treatment.

\section{Statistics}

Each assessment item was measured before treatment, 
immediately after treatment, and 1 week after treatment. Differences in age and symptom period of the subjects between three groups were analyzed by one-way analysis of variance and differences in gender ratio between three groups were analyzed by chi-square tests using SPSS ver. 17.0 (SPSS Inc., Chicago, IL, USA). To compare average value of each assessment item between groups, repeated measures analysis of variation was used and when the result of the analysis of variation was statistically significant, the differences between groups were judged using post-hoc tests. Change of each value before and during treatment period was considered to be statistically significant when $\mathrm{p}$-value of paired t-test was less than 0.05 .

\section{RESULTS}

\section{Characteristics of subjects}

Nineteen patients were males and 41 patients were females totaling 60 subjects, and they were divided into three groups: trigger point injections group (group 1, 20 patients), trigger point injections followed by 30 seconds of ischemic compression group (group 2, 20 patients), and trigger point injections followed by 60 seconds of ischemic compression group (group 3, 20 patients).

Average age of the patients was $43.15 \pm 11.55$ years, aver- age duration of disease was $7.42 \pm 4.36$ weeks and there were no significant differences in the average age and average duration of disease between three groups. In addition, there were more female patients than male patients in every group but there were no differences in gender ratio between three groups. All the patients developed twitch responses when they underwent trigger point injections therapy (Table 1). Some of the patients had minor bleeding after trigger point injections but the bleedings were easily controlled by gentle compression with gauzes. There were no complications such as hematoma or infection.

\section{Change in visual analogue scale}

There was no significant difference in VAS value between three groups. VAS value after treatment was significantly lower than before treatment in every group $(\mathrm{p}<0.05)$. VAS value of group 2 and group 3 decreased by lapse of time significantly more than that of group 1 $(\mathrm{p}<0.05)$, but there were no significant differences between group 2 and group 3 (Table 2).

\section{Change in pressure pain threshold}

There were no significant differences in PPT value between three groups before treatment. PPT value in-

Table 1. General characteristics of patients $(n=60)$

\begin{tabular}{lccc}
\hline \multicolumn{1}{c}{ Characteristic } & Group 1 $(\mathbf{n = 2 0})$ & Group 2 $(\mathbf{n = 2 0})$ & Group 3 (n=20) \\
\hline Age $(\mathrm{yr})$ & $44.35 \pm 9.34$ & $44.45 \pm 12.73$ & $40.65 \pm 12.45$ \\
Gender & & & \\
$\quad$ Male & $7(35)$ & $7(35)$ & $5(25)$ \\
Female & $13(65)$ & $13(65)$ & $15(75)$ \\
Symptom durations (wk) & $6.65 \pm 3.96$ & $8.00 \pm 4.21$ & $7.60 \pm 4.97$ \\
\hline
\end{tabular}

Values are presented as number (\%) or mean \pm standard deviation.

Table 2. Changes of visual analogue scale after treatment

\begin{tabular}{llcc}
\hline & Group 1 & Group 2 & Group 3 \\
\hline Pre-treatment & $5.90 \pm 1.10$ & $6.65 \pm 1.93$ & $6.95 \pm 1.43$ \\
Immediately after treatment & $4.00 \pm 1.72^{\text {a) }}$ & $5.15 \pm 1.98^{\text {a) }}$ & $5.20 \pm 1.85^{\text {a) }}$ \\
1 week after treatment & $3.70 \pm 0.86^{\text {a) }}$ & $2.35 \pm 1.23^{\text {a) }}$ & $2.75 \pm 0.79^{\text {a) }}$ \\
$\mathrm{T}^{\text {b) }}$ & & $c$ & $c$ \\
\hline
\end{tabular}

Values are mean \pm standard deviation.

${ }^{a)} \mathrm{p}<0.05$ for paired $\mathrm{t}$-test.

${ }^{b)} \mathrm{p}$-values were tested by one-way analysis of variances among groups.

${ }^{\mathrm{b})} \mathrm{T}$, same letters indicate non-significant differences between groups based on Tukey's multiple comparison test. 
Table 3. Changes of pressure pain threshold after treatment $\left(\mathrm{kg} / \mathrm{cm}^{2}\right)$

\begin{tabular}{llcc}
\hline & Group 1 & Group 2 & Group 3 \\
\hline Pre-treatment & $5.91 \pm 2.12$ & $6.38 \pm 1.87$ & $6.28 \pm 2.89$ \\
Immediately after treatment & $7.35 \pm 2.81^{\text {a) }}$ & $9.09 \pm 2.08^{\text {a) }}$ & $9.30 \pm 2.66^{\text {a) }}$ \\
1 week after treatment & $6.58 \pm 2.13^{\text {a) }}$ & $8.79 \pm 2.01^{\text {a) }}$ & $9.28 \pm 2.87^{\text {a) }}$ \\
$\mathrm{T}^{\text {b) }}$ & & c & c \\
\hline
\end{tabular}

Values are mean \pm standard deviation.

${ }^{\text {a) }} \mathrm{p}<0.05$ for paired t-test.

b) $\mathrm{p}$-values were tested by one-way analysis of variances among groups.

b) T, same letters indicate non-significant differences between groups based on Tukey's multiple comparison test.

Table 4. Changes of Korean neck disability index after treatment

\begin{tabular}{|c|c|c|c|}
\hline & Group 1 & Group 2 & Group 3 \\
\hline Pre-treatment & $15.75 \pm 5.50$ & $15.45 \pm 8.02$ & $17.65 \pm 8.39$ \\
\hline 1 week after treatment & $12.15 \pm 4.65^{\mathrm{a})}$ & $7.70 \pm 4.38^{\mathrm{a})}$ & $8.10 \pm 3.89^{a)}$ \\
\hline $\mathrm{T}^{\mathrm{b})}$ & & $\mathrm{c}$ & c \\
\hline
\end{tabular}

Values are mean \pm standard deviation.

${ }^{\text {a) }} \mathrm{p}<0.05$ for paired t-test.

b) $\mathrm{p}$-values were tested by one-way analysis of variances among groups.

${ }^{b} \mathrm{~T}$, same letters indicate non-significant differences between groups based on Tukey's multiple comparison test.

Table 5. Changes of active range of motions after treatment

\begin{tabular}{llll}
\hline & Group 1 & Group 2 & Group 3 \\
\hline Pre-treatment & $32.65 \pm 8.38$ & $38.70 \pm 9.88$ & $38.65 \pm 3.25$ \\
Immediately after treatment & $35.90 \pm 10.89^{\text {a) }}$ & $41.85 \pm 10.55^{\text {a) }}$ & $41.60 \pm 4.55^{\text {a) }}$ \\
1 week after treatment & $39.55 \pm 6.92^{\text {a) }}$ & $47.00 \pm 7.20^{\text {a) }}$ & $45.40 \pm 4.01^{\text {a) }}$ \\
\hline
\end{tabular}

Values are presented as mean \pm standard deviation.

${ }^{a)} \mathrm{p}<0.05$ for paired t-test.

creased significantly after treatment than before treatment in every group $(\mathrm{p}<0.05)$. PPT value of group 2 and group 3 increased by lapse of time significantly more than that of group $1(\mathrm{p}<0.05)$, but there were no significant differences between group 2 and group 3 (Table 3 ).

\section{Change in neck disability index}

There were no significant differences in NDI value between three groups before treatment. NDI value increased significantly 1 week after treatment than before treatment in every group $(\mathrm{p}<0.05)$. NDI value of group 2 and group 3 increased by lapse of time significantly more than that of group $1(\mathrm{p}<0.05)$, but there were no significant differences between group 2 and group 3 (Table 4).

\section{Change in range of motion of the neck}

Active range of motion (ROM) of the neck increased significantly after treatment in every group $(\mathrm{p}<0.05)$, but there were no statistically significant differences between three groups. And before treatment, active ROM of the neck of group 1 was significantly smaller than that of group 2 and group 3 (Table 5).

\section{DISCUSSION}

MPS is classified as a local pain syndrome which is characterized by local tenderness, myofascial pain trigger points and typical referred pain, and is known to be a very common clinical syndrome [17]. The most typical symptom of MPS is pain and there are various treatment methods to relieve this pain such as local injection, phys- 
iotherapy, dry needling, ischemic compression, stretching, etc. $[5-7,18,19]$. These methods commonly decrease muscles shortening and increase local blood flows of trigger points [11].

Of these methods, trigger point injection is well known to be an effective treatment for MPS. Ceccheerelli et al. [20] compared needling at skin level of trigger points with needling in deeper muscle layer and insisted that the latter is more efficient. Cummings and White [21] reported that stimulation at the trigger point itself causes pain relieving effects regardless of injected agents. In this study, we also identified significant pain reliefs after local injections therapy and this result is consistent with that of previous studies.

Kostopoulos et al. [10] compared efficacy of ischemic compression, passive stretching, and the combination of ischemic compression and passive stretching for the first time and reported that the combination was significantly more effective for pain reliefs than the others. Lake et al. [22] evaluated the efficacy of ischemic compression on 13 patients with 40 myofascial trigger points and reported that ischemic compression was significantly efficient for treatment in comparison with control group, but did not define the optimal level of ischemic compression.

Hanten et al. [23] studied the efficacy for the combination of ischemic compression and stretching for patients with MPS on neck and upper back. Patients underwent the combination therapy for 5 days and then the duration of pain sensations in 24 hours, PPT and VAS measured 3 days after the treatment were compared with those measured before treatment. There were significant improvements in PPT and VAS.

There have been studies on efficacy of ischemic compression, but no study on efficacy of combination of trigger point injection and ischemic compression. The purpose of this study is to evaluate the efficacy of such combination therapy.

This is the first study on the combination of trigger point injection and ischemic compression and as a result, both trigger points injection and the combination therapy showed significant improvements in PPT, active ROM of the neck, VAS, and NDI. However, the combination therapy was only significantly more efficient than trigger point injections in assessment items excluding active ROM of the neck.

Ischemic compression induces transient local ischemia and is followed by hyperemic reperfusion after decompression. Increased blood flows elicit increments of aerobic metabolism and adenosine triphosphate and this results in treatment effects [10]. Hence, it is considered that combination of reducing muscle shortening by physical stimulation on trigger points and increased blood flow results in better treatment effects.

In this study, there were no significant differences between group 2 and group 3. Gulick et al. [24] reported that PPT value increased significantly in patients treated with ischemic compression of 30 seconds compared to that of untreated patients. Herein, there were no differences in treatment effects between group 2 and group 3; and thus, it is considered that transient local ischemia can be achieved with only 30 seconds of compression. Hence, it is suggested that compression for 30 seconds or more which causes unnecessary pains for patients should be avoided.

The number of subjects was small and the follow-up period was short in our study. In addition, we did not identify the optimal duration of ischemic compressions shorter than 30 seconds. Further studies would be required to confirm our findings.

In conclusion, it is suggested that the combination of trigger point injections and ischemic compression is more efficient for treatment of MPS than trigger point injections only, and ischemic compression for 30 seconds or more has no further effects.

\section{CONFLICT OF INTEREST}

No potential conflict of interest relevant to this article was reported.

\section{REFERENCES}

1. Chaiamnuay P, Darmawan J, Muirden KD, Assawatanabodee P. Epidemiology of rheumatic disease in rural Thailand: a WHO-ILAR COPCORD study. Community Oriented Programme for the Control of Rheumatic Disease. J Rheumatol 1998;25:1382-7.

2. Rubin D. Myofascial trigger point syndromes: an approach to management. Arch Phys Med Rehabil 1981; 62:107-10.

3. McNulty WH, Gevirtz RN, Hubbard DR, Berkoff GM. Needle electromyographic evaluation of trigger point 
response to a psychological stressor. Psychophysiology 1994;31:313-6.

4. Han SC, Harrison P. Myofascial pain syndrome and trigger-point management. Reg Anesth 1997;22:89101.

5. Rickards LD. The effectiveness of non-invasive treatments for active myofascial trigger point pain: a systematic review of the literature. Int J Osteopath Med 2006;9:120-36.

6. Hou CR, Tsai LC, Cheng KF, Chung KC, Hong CZ. Immediate effects of various physical therapeutic modalities on cervical myofascial pain and trigger-point sensitivity. Arch Phys Med Rehabil 2002;83:1406-14.

7. Aguilera FJ, Martin DP, Masanet RA, Botella AC, Soler LB, Morell FB. Immediate effect of ultrasound and ischemic compression techniques for the treatment of trapezius latent myofascial trigger points in healthy subjects: a randomized controlled study. J Manipulative Physiol Ther 2009;32:515-20.

8. Hameroff SR, Crago BR, Blitt CD, Womble J, Kanel J. Comparison of bupivacaine, etidocaine, and saline for trigger-point therapy. Anesth Analg 1981;60:752-5.

9. Hong CZ. Lidocaine injection versus dry needling to myofascial trigger point: the importance of the local twitch response. Am J Phys Med Rehabil 1994;73:25663.

10. Kostopoulos D, Nelson AJ, Ingber RS, Larkin RW. Reduction of spontaneous electrical activity and pain perception of trigger points in the upper trapezius muscle through trigger point compression and passive stretching. J Musculoskelet Pain 2008;16:266-78.

11. Simons DG, Travell JG, Simons LS. Myofascial pain and dysfunction: the trigger point manual. 2nd ed. Baltimore: Williams \& Wilkins; 1999.

12. Song KJ, Choi BW, Kim SJ, Yoon SJ. Cross-cultural adaptation and validation of the Korean version of the neck disability index. J Korean Orthop Assoc 2009;44: 350-9.

13. Fryer G, Hodgson L. The effect of manual pressure release on myofascial trigger points in the upper tra- pezius muscle. J Bodyw Mov Ther 2005;9:248-55.

14. Fischer AA. Pressure algometry over normal muscles: standard values, validity and reproducibility of pressure threshold. Pain 1987;30:115-26.

15. Brennum J, Kjeldsen M, Jensen K, Jensen TS. Measurements of human pressure-pain thresholds on fingers and toes. Pain 1989;38:211-7.

16. Reeves JL, Jaeger B, Graff-Radford SB. Reliability of the pressure algometer as a measure of myofascial trigger point sensitivity. Pain 1986;24:313-21.

17. Han TR, Bang MS. Myofascial pain. In: Kang YK, editor. Rehabilitation medicine. 3rd ed. Seoul: Koonja; 2008. p. 887-96.

18. Melzack R, Wall PD. Pain mechanisms: a new theory. Science 1965;150:971-9.

19. Sjolund BH, Eriksson MB. Endorphins and analgesia produced by peripheral conditioning stimulation. Adv Pain Res Ther 1979;3:587-92.

20. Ceccheerelli F, Bordin M, Gagliardi G, Caravello M. Comparison between superficial and deep acupuncture in the treatment of the shoulder's myofascial pain: a randomized and controlled study. Acupunct Electrother Res 2001;26:229-38.

21. Cummings TM, White AR. Needling therapies in the management of myofascial trigger point pain: a systematic review. Arch Phys Med Rehabil 2001;82:98692.

22. Lake DA, Wright LL, Cain J, Nail R, White L. The effectiveness of ischemic pressure and ischemic pressure combined with stretch on myofascial trigger points. J Orthop Sports Phys Ther 2009;39:A70.

23. Hanten WP, Olson SL, Butts NL, Nowicki AL. Effectiveness of a home program of ischemic pressure followed by sustained stretch for treatment of myofascial trigger points. Phys Ther 2000;80:997-1003.

24. Gulick DT, Palombaro K, Lattanzi JB. Effect of ischemic pressure using a Backnobber II device on discomfort associated with myofascial trigger points. J Bodyw Mov Ther 2011;15:319-25. 